\title{
Influence of personality traits and moral values on employee well-being, resilience and performance: A cross-national study
}

\begin{abstract}
Research examining the relationship at the interface of personality, values, moral foundations and its impact on employees' subjective well-being, resilience, job performance and satisfaction is almost non-existent. This study addresses this Special Issue's call focusing on the key antecedents and consequences of resilience on individual and/or organizational level outcomes. It does so by analyzing data from two different, through comparative cross-national studies in Australia and India. Employing a quantitative survey method, we collected data from 195 respondents in Australia and 257 respondents from India. Employing the core theory of moral foundations in association with its relationships with individual personality, values, well-being and resilience, our findings suggest a significant relationship between personality traits and individual moral foundations, and psychological wellbeing via values. The study offers distinctive contributions to the literatures on well-being, resilience and moral foundations theory. Specifically, personality trait of extroversion influences power and achievement or self-enhancement values through individualized moral foundations. Second, the study found values of benevolence and universalism, or compassionate values, form the basis for biological mechanisms of resilience through individual moral foundations of fairness/harm care. The paper concludes with implications for theory and practice.
\end{abstract}

Keywords: Extraversion; Self-enhancement and Compassionate values; Moral Foundations; Well-being; Resilience, Job Satisfaction,

\section{INTRODUCTION}

In a global environment that typifies high levels of immigration, economic crises, and fear of terrorism, among others (Hobfoll, Hall, Canetti-Nisim, Galea, Johnson, \& Palmieri, 2007; Kellezi, Reicher, \& Cassidy, 2009), building individual and organizational resilience and well-being is pivotal for individuals and society to prevail (Williams, \& Shepherd, 2016). Resilient individuals have an ability to engage positively in life, aim to maintain social cohesion, and achieve belongingness in social activities, which eventually promotes wellbeing (Athota, 2016; Lyubomirsky, King, \& Diener, 2005; Marks \& Shah, 2005). While there is an increasing interest in employee well-being and resilience in times of change, the body of 
literature is scant in relation to its micro-foundations in terms of how an individual's personality, values and moral foundations affect the same (Gary \& Bates, 2011). Addressing this shortcoming in the literature, we uncover through the theoretical knowledge of personality, values, moral foundations on how it informs the current understandings of employee well-being, resilience and at work. Further, as Aristotle argued in his book on Nicomachean Ethics that eudaimonia, which translates as 'happiness' or 'well-being', it requires moral living for achieving Eudaimonia. Theories on personality traits have further provided an understanding on the mechanisms of wellbeing. Therefore, our study argues that it is logical to explore the association between personality, morality and well-being, and their implications on workplace resilience and success.

Morality plays an important role in our social life, providing justice, welfare and bonding among individuals and groups (Suhler \& Churchland, 2011). Morality also provides psychological mechanisms such as values, virtues, norms and structural foundations for individuals and groups to live in harmony (Haidt, 2008). Pizarro \& Salovey (2002) suggested that morality is critical for the survival of a society and one should focus on becoming more resilient. Jonathan Haidt and his colleagues developed the Moral Foundations Theory (MFT), which focuses on five comprehensive dimensions of moral foundations: Harm/care, Fairness/reciprocity, Ingroup/loyalty, Authority/respect, and Purity/sanctity (Graham, Nosek, Haidt, Iyver, Koleva \& Ditto, 2011; Haidt, Graham \& Nosek, 2009). While MFT has provided the basis for much empirical inquiry, there is limited research that analyses its relationship with resilience, employee well-being, job performance and satisfaction, especially in a cross-national and cross-cultural context. It is in this neglected area that our study aims to contribute. Overall, this study contributes to this special issue call's first bullet point by focusing on identifying the key antecedents and consequences of resilience that have an impact on individual and/or organizational level outcomes. The research achieves this by 
examining the individual level psychological factors of personality, values and moral foundations and its relationship with employee well-being, resilience and its influence on employee job satisfaction and performance.

The above inquiry is relevant in the current global context, as individual and organizational survival requires values such as justice, rights, individual autonomy, kindness, gentleness and nurturance. These values are an integral part of developing individual moral foundations of fairness/reciprocity and harm/care. Arguably, resilient individuals with high individual moral foundations can have a positive impact on collective well-being (Graham et al., 2011; Haidt, Graham \& Nosek, 2009). However, research on the association between moral foundations and personality is still in its early stages (Gary \& Bates, 2011).

The extant literature suggests that biological personality traits and values remain stable over sustained periods of time (Cloninger et al., 1993; Cloninger, 1987; Goldberg, 1999; Schwartz, 1992, 1994). To this end, the overarching research question guiding this research's first study is (1) Do biologically-based personality traits predicts moral foundations through values?; and through a subsequent study in a different cultural and national context, this research considers two further research questions: (2) Do biologically-based personality traits predicts moral foundations through values?, and (3) Does personality, values and moral foundations influence an individual's resilience and well-being? Both these questions are pertinent to the special issue's call as well as are critical attributes in dealing with today's turbulent and uncertain times. Such an inquiry is timely and relevant because an individual's value systems and traits drive their behaviors and actions (Furnham, Hyde, \& Trickey, 2014). We answer the above questions by analyzing data from two cross-national studies in Australia and India. In the first study, we analyze survey data from 195 respondents in Australia to test the relationship between personality traits, values and moral foundations. We extend this finding in our second study, wherein, we examine the impact of personality traits, 
values and moral foundations on the subjective well-being, resilience, job performance and job satisfaction of 257 respondents from India.

Similarly, studies on moral intensity highlight the importance of value and belief systems of individuals in explaining their ethical and unethical behaviors in situations that have a moral component in them, thus aiding managerial decision-making (Dukerich, Waller, George, \& Huber, 2000; O’Leary-Kelly \& Bowes-Sperry, 2001). Individuals' personality traits and values can in part explain the resilient nature of individuals who survive in such environments. To this end, employing the core theory of moral foundations along with its relationships theories of personality and values, we seek to better understand how these have an impact on employees' resilience, well-being and job satisfaction and performance.

The rest of the paper is organized as follows. The paper begins by reviewing the literature on personality, values, moral foundations theory, well-being and resilience. Based on our review of literature and the gaps identified, the paper presents the study's conceptual framework. Next, the study's research questions and hypotheses are developed followed by data analysis and findings. The paper then provides discussion, implications of the study's findings on the current theorizations of resilience and well-being and highlights future research directions.

\section{REVIEW OF LITERATURE}

\section{Personality Traits}

Personality is defined as "the set of psychological traits and mechanisms within the individual that are organized and relatively enduring and that influence his or her interactions with, and adaptations to, the intra-psychic, physical and social environments" (Larsen \& Buss, 2014, p. 4). Previous research has established the association between the Big-Five personality traits (i.e., extraversion, agreeableness, conscientiousness, openness to 
experiences and emotional stability) and human values (see De Raad \& van Oudenhoven, 2008; Stankov, 2007). Research also points to the biological base of the Big Five personality traits (Cloninger et al., 1993) and values (Athota \& O’Connor, 2014; Schwartz, 1992). Both personality traits and values are consistent over time and situations (Dollinger, Leong, \& Ulicni, 1996). We specifically focus on extraversion, which refers to preference of being in the company of others and being talkative and assertive and Neuroticism, which refers to emotional instability and is a state that is prone to negative emotions, anxiousness and insecurity) (Raynor \& Levine, 2009). Research has shown that extraversion has significant conceptual overlap with stimulation (Patterson et al., 1987). Many personality traits related to moral foundations have already been shown to be moderately heritable, including, extraversion, neuroticism, harm, and avoidance (Goldberg 2014; Keller, Coventry, Heath, \& Martin, 2005). Larsen \& Buss (2014) provided logical connection between personality traits of extraversion and neuroticism and moral reasoning. We suggest that extraversion and neuroticism provide intense tendencies that explain feelings, thoughts and behavior patterns of values (Power, achievement, universalism, and benevolence) and moral foundations (Individualized moral foundations). These conceptual overlaps help us to understand how people build bonds, influence one another and establish social clusters.

\section{Values}

Social moral systems play an important role in creating moral values (e.g., Athota \& O’Connor, 2014). Schwartz (1994) points out that values "serve as guiding principles in the life of a person or other social entity" (p.21). Values are the fundamental social and biological needs of human beings (Athota \& O’Connor, 2014; Schwartz, 1992; Rokeach, 1973). Theorists have also argued that values are a manageable set of constructs, which provide a foundation for individuals and groups to live in cooperation and eventually promote collective well-being (Graham et al., 2009; Rokeach, 1979). Schwartz (1992, 1994) presented 
a plausible structure of values and argues that human values are driven from individuals' biological needs, coherent social interaction, need for survival through resilience and welfare through promoting collective well-being among individuals and groups.

In this paper, however, we focus on two opposing sets of values: self-enhancement values of power and achievement and compassionate values which enhance others; and values of universalism and benevolence (Schwartz, 1992, 1994). We focus on self-enhancement values and self-transcendence values in their opposing nature. These self-enhancement values and self-transcendence values function in opposite directions. For example, individuals who score

high on achievement are driven by success and demonstration of their competence. Further, power-oriented individuals are ambitious and seek authority, dominance and social status (Allport, 1961: Schwartz, 1992, 1994). Both achievement and power individuals is driven by self-interest rather than serving others. Individuals who score high universalism and benevolence are focus on self-transcendence and focus on the welfare of others. Benevolence is associated with a focus on the welfare of individuals within the group and universalism is associated with tolerance, understanding and welfare for all. Our focus is on values power and achievement (self-enhancement), and universalism and benevolence (enhancement of others beyond personal interest), because of their opposing nature in their function (Athota \& O’Connor, 2014; Schwartz, 1992). Conceptually, we argue that these values influence wellbeing and resilience.

\section{Moral Foundations Theory}

According to Haidt and Kesebir (2010, p. 800), the domain of morality is very broad and related to many important aspects of human existence: "Moral systems are interlocking sets of values, virtues, norms, practices, identities, institutions, technologies, and evolved psychological mechanisms that work together to suppress or regulate selfishness and make 
social life possible”. The MFT specifically measures moral foundations/intuitions through individualized and group oriented moral foundations. Individualized moral foundations are harm/care (it underpins virtues of kindness, gentleness, and nurturance) and fairness/reciprocity (it generates ideas of justice, rights, and autonomy) (Haidt, Graham \& Nosek, 2009). Similarly, group binding moral foundations/intuitions have been conceptualized in terms of in-group/loyalty (it underpins virtues of patriotism and selfsacrifice for the group), authority/respect (it underpins virtues of leadership and followership, including deference to legitimate authority and respect for traditions), and purity/sanctity (it underpins religious notions of striving to live in an elevated, less carnal, more noble way) (Haidt et al., 2009).

Subsequently, the MFT was expanded to include a sixth dimension of moral foundation freedom/oppression (Haidt, 2012). Prior to the development of MFT, Turiel, Hildebrandt, and Wainryb (1991) explored the conceptual overlap between human values and moral foundations. More specifically, welfare and fairness (e.g. universalism and benevolence) are underpinnings for both Schwartz's (1992) values and Graham et al.'s (2011) morality. And these foundations have implications for well-being (Kesebir \& Diener, 2008). We argue moral systems, specifically, individualized moral foundations, provide foundations for individual and organizational resilience and well-being. Further, well-being has been noted as a key predictor of individual resilience (Dunn, Iglewicz, \& Moutier, 2008). However, there is little evidence on under what conditions moral foundations impact an individual's resilience and well-being. The following literature and hypotheses provide support on the association between personality traits, values, moral foundations, well-being, resilience, job satisfaction and job performance. 


\section{Employee Well-being}

Building on employees' resilience and subjective well-being is central to developing the psychological strength of individuals for the design and implementation of innovations at the workplace. Wellbeing is referred to as "a generalized feeling of happiness" (Schmutte and Ryff, 1997, p. 551). Wellbeing is also defined as 'the overall evaluation of one's life, as the overall quality of an employee's experience and functioning at work, including life satisfaction and positive affect which influence individual performance' (Huang, Ahlstrom, Lee, Chen \& Hsieh, 2016, p. 299). Diener, Emmons, Larsen, \& Griffin (1985) measured wellbeing through their Satisfaction with Life Scale (SWLS). Emotional intelligence is strongly associated with psychological wellbeing (Carmeli, Yitzhak-Halevy \& Weisberg, 2009) and social wellbeing (Carmeli \& Gittell, 2009). Empirical evidence suggests a strong overlap between psychological wellbeing and emotional competence (Brackett \& MayIer, 2003). Therefore, measuring emotional competence helps us understand psychological wellbeing. Therefore, we note, for the purposes of this paper that emotional intelligence helps us to understand the construct of employees' emotional wellbeing, which can be measured through understanding individual's ability to manage their own and others' emotions and social relationships (Goleman, 1995; Salovey \& Mayer, 1990).

\section{Resilience}

Lamb \& Cogan (2016) identified how strategies of building resilience have a positive impact on employees' subjective well-being outcomes. Much of the work on resilience largely focuses either on its psychological processes or on organizational and managerial practices impacting resilience at workplace. There is an emerging body of research that links developing resilience capability with increased levels of employees' subjective well-being, psychosocial outcomes, job satisfaction and performance (Grant et al., 2009; Robertson, 
Cooper, Sarkar \& Curran, 2015; Shepherd, Wiklund, \& Haynie, 2009). In the past decade, the construct of resilience has been extensively examined in research on positive psychology (Fredrickson, 2001). Dahms (2010) defined "resilience is the ability of an organisation to anticipate and respond to uncertainty in a complex adaptive environment, i.e. its adaptive capacity." (p. 27). According to Merriam-Webster (2015) dictionary resilience is "the ability to become strong, healthy, or successful again after something bad happens". Another definition of resilience notes, "Organizational resilience includes the ability of an organization to withstand systematic discontinuities, and the capability to adapt to new environments has emerged from different risk sources" (Tadić, Aleksić, Stefanović \& Arsovski, 2014, p. 1). Resilience has been noted to have an influence on emotional wellbeing and life satisfaction (Liu, Wang, \& Lü, 2013). Resilience plays a crucial role in countering traumatic experiences through positive emotions (Fredrickson et al., 2003; Ong, Bergeman, Bisconti, \& Wallace, 2006; Ucbasaran, Shepherd, Lockett, \& Lyon, 2013).

However, to the best of our knowledge, prior research on resilience has not focused on the relationship between personality traits, values and moral foundations. Exploring this aspect is relevant as an individual's personality traits and moral foundations form the very basis for developing applied aspects of resilience, which have practical implications for the workplace. Resilience in this context is defined as "the capacity of the individual to effectively modulate and monitor an ever-changing complex of desires and reality constraints" (Block \& Kremen, 1996, p. 359).

In a recent study, resilience was found to have an impact on individual traits, capacity and processes (Kossek \& Perrigino, 2016). Resilience is therefore, vital in dealing with organizational demands in complex environments (Pieters \& Young, 1999). Specifically, “Occupational resilience involves (1) multiple conceptual strands related to accessing 
resources (trait, capacity, and processes); (2) positive and negative triggers that are occupationally distinguished; (3) different resilience types (cognitive, emotional, and physical) that vary in need, breadth, and importance across occupations; (4) a dynamic phenomenon that occurs within and across career stages; (5) both content-general, and jobspecific occupational tensions; and (6) work and non-work domains (Kossek, \& Perrigino, 2016, P.2)”.

Resilience has been noted to provide individuals and organizations the ability to implement strategic decision-making in a changing environment (Hamel \& Valikangas, 2003). These authors further contend that organizations that engage in continuous levels of new learning and innovation, develop resilient business models and are therefore better placed to develop individual- and organizational-level resilience. Resilience also plays an important role in developing organizational ambidexterity (Junni, Sarala, Taras, \& Tarba, 2013) and found to be beneficial during times of organizational change (Shin, Taylor \& Seo, 2012).

Most importantly, although social environments play an in important role in promoting individual's wellbeing, established research suggest that individual predispositions based on values and personality play pivotal role in providing base for social environments. It can be argued that values and personality traits play nature's role and environmental factors play nurture role. There is a trait-based argument for resilience. For example, Kobasa (1979) suggested that "Persons who experience high degrees of stress without falling ill (that) have a personality structure differentiating them from persons who become sick under stress" (p. 3). Contrada (1989) argued that "a personality dimension that is believed to confer resistance against the effects of psychological stress" (p. 896). Therefore, it is important to understand the association between values, personality traits, resilience and wellbeing. In what follows 
the paper further notes values, personality traits, moral foundations and its association with resilience and wellbeing.

Relationships between Personality, Values, Well-being and Resilience

Schwartz's (1992) values have a tension in the intrinsic nature of their manifestation. For example, hedonism opposes conformity and tradition, stimulation opposes security, and universalism and benevolence values oppose power and achievement values. Universalism and benevolence values by nature promote well-being for others; power and achievement promote self-centeredness. For this reason, we focus on the values of power and achievement because of their self-enhancement and self-transcendence values of universalism and benevolence (Schwartz, 1992; 2005). Based on Schwartz's (1992) values theory, we suggest universalism (social justice, equality, broadmindedness) and benevolence (helpful, forgiving, responsible) promote well-being, because of their nature of care and welfare for others. Overall, these values have logical implications to promote resilience and well-being in individuals and organizations. For our Study 1, we utilize the literature on personality traits, extraversion and neuroticism based on their conceptual implications on values, and moral foundations; and in Study 2, we focus on personality, resilience, well-being and job performance and job satisfaction to address our research question (see Figures $1 \& 2$ for strengths of the results found).

Insert Figure 1 about here

\section{Hypotheses}

Study 1 hypotheses deal with personality, values and moral foundations, whereas in Study 2, the relationship between personality, values, moral foundations, well-being, resilience, job 
satisfaction and job performance is hypothesized. Research suggests that there are intrinsic differences between values and moral foundations. Moral foundations theory links anthropological and evolutionary accounts of morality (Haidt \& Graham, 2007; Haidt \& Joseph, 2004). Moral intuitions derive from innate psychological mechanisms that coevolved with cultural institutions and practices (Richerson \& Boyd, 2005). Moral foundations are the psychological systems that allow feelings and intuitions to enable ethical conduct of social life possible (Graham, Haidt, \& Nosek, 2009).

There is conceptual overlap between extraversion (Cost \& McCrae, 1992) and individual moral foundations. Individuals who score high on extraversion generally exhibit energetic behavior, are outspoken in social situations and driven by social reward (Cost \& McCrae, 1992; Goldberg 2014). Extraverts by nature enjoy interaction with others. Individual moral foundations, harm/care and fairness/reciprocity generally exhibit social concern and promote positive social interaction (Haidt \& Graham, 2007). Both extraversion and individual moral foundations generally work in association of people. Individuals who score high on neuroticism are self-conscious, anxious, likely to keep things to themselves and be sensitive in social situations (Cost \& McCrae, 1992; Goldberg 2014). Extraversion also correlates with emotional competence (McCrae, 2000) and happiness (Costa \& McCrae, 1980). Emotional competence and wellbeing have personality components in their operation (Mayer \& Salovey, 1995). Strong conceptual overlap can be found between emotional competence and extraversion (McCrae, 2000; Mayer \& Salovey, 1995). Individuals who score low on neuroticism generally exhibit extraversion dispositions such as positive emotions and satisfaction (De Neve \& Cooper, 1998). We suggest that either low or high scores on extraversion influences the interaction of moral foundations. Goleman (1996) states, "The bedrock of character is self-discipline; the virtuous life" (p.284). Therefore, we suggest that 
there is a logical consistency in that personality trait, extraversion is likely to be associated with individual moral foundations in predicting emotional wellbeing. Hence, we propose that:

Hypothesis 1: Extraversion is associated with emotional wellbeing via individual moral foundations of harm/care and fairness/reciprocity.

Extraversion has been found to be associated with Schwartz's values of power and achievement, benevolence and universalism (Roccas et al., 2002; De Raad \& van Oudenhoven, 2008). Research points that extraversion and values are consistent over time and across situations (Dollinger, Leong, \& Ulicni, 1996). Boyatzis, Goleman \& Rhee (2000) suggest that extraversion was also associated with communication and leadership. Curtis, Billingslea, \& Wilson (1998) in their research, found significant associations between moral maturity and socialization (extraversion). Research further suggests that extraversion (e.g., Kochanska, Aksan, Penney, \& Doobay, 2007) is associated with reward-seeking conditions. Power and achievement, on the other hand are associated with self-enhancement values (Schwartz, 2006), which offer only short-term reward and likely to interfere with the more salient long-term rewards. Emotional competence, which is driven by optimism, impulsivity, empathy and management of emotions (Petrides and Furnham, 2000). Haidt states (2001), "Moral emotions such as sympathy may sometimes be inputs to the reasoning process" (p. 814). Moral elements such as self-discipline and virtuous living was associated with emotional wellbeing (Goleman, 1996). The key difference between moral foundations and values is that moral foundations are the result of moral intuitions and values, which are the result of individuals' biological needs. The biologically based values of power and achievement, and personality trait extraversion are driven by their nature. Individuals who score high on individual moral foundations are extrinsic in nature and have their association to emotional wellbeing. Therefore, we hypothesize that: 
Hypothesis 2: Power and achievement plays a positive mediating role between extraversion and individualized moral foundations of harm/care and fairness/reciprocity in predicting emotional wellbeing.

Similarly, values of universalism and benevolence also focus on others. Therefore, we suggest it plays a mediating role between individualized moral foundations and extraversion.

According to Schwartz, the values of universalism and benevolence are concern for wellbeing and welfare for people. Specifically, universalism is associated with welfare for all people, and benevolence is associated with welfare and care for those in frequent personal contact (Schwartz, 1992). As discussed above, moral foundations are concerned with individuals in society. Morally significant emotions like compassion and empathy are integral part of emotional wellbeing (Eisenberg, 2000). Emotional wellbeing is associated with selfcontrol and well as character development (Pizzaro, 2000). Therefore, there is logical consistency to argue that universalism and benevolence influence emotional wellbeing via individual moral foundations. Based on such conceptual associations, we propose that:

Hypothesis 3: Universalism and benevolence plays a positive mediating role between extraversion and individualized moral foundations of harm/care and fairness/reciprocity in predicting emotional wellbeing.

\section{Study 2 Hypotheses}

\section{Personality, Resilience and Well-being}

Research suggests that personality plays an important role in predicting resilience and wellbeing (DeNeve \& Cooper, 1998; Diener \& Lucas, 1999). Specifically, extraversion by nature warmth, gregariousness, assertiveness, seeking excitement and exhibit positive emotions (Goldberg et al., 2006). These qualities have animpact on an individual's resilience and well- 
being (e.g., Ryff, Keyes \& Shmotkin, 2002). However, more detailed research is needed on personality, moral foundations, values and its association with resilience and well-being.

Graham et al. (2011) suggest that environment can influence individuals' moral differences. For example, a well-reasoned family and social influences promote harm/care and fairness/reciprocity, whereas a narrow view of environmental factors often leads to second order of modules such as in-group/loyalty, authority/respect, purity/sanctity. We argue that individual moral foundations are superior in achieving well-being and resilience as compared to binding moral foundations. We suggest that individualized moral foundations of harm/care and fairness/reciprocity (Haidt, Graham \& Nosek, 2009), by nature promote resilience and well-being at the individual and organizational levels. Specifically, fairness/reciprocity actively promotes justice, rights, and individual autonomy. Harm/care promotes virtues of kindness, gentleness and nurturance. Resilient individuals are generally known to stand for virtues of justice, courage, individual rights and autonomy (e.g., Kesebir \& Diener, 2008). We argue that differences in individual level (harm/care, fairness/reciprocity) and group binding (in-group/loyalty, authority/respect, purity/sanctity) moral foundations can be partially accounted for by personality traits and values, which have theoretical support in both data sets and further found support for individual moral foundations to positively and significantly impact employee resilience at workplace. We specifically focus on extraversion based on the theoretical association with resilience (DeNeve \& Cooper, 1998; Diener \& Lucas, 1999). Extraverts by nature are outgoing and tend to have a resilient spirit (Athota \& Roberts, 2015). Therefore, we hypothesize that:

Hypothesis 4: Extraversion is associated with resilience, via individualized moral foundations.

Based on the literature, we suggest that extraversion play an important role in influencing well-being (DeNeve \& Cooper, 1998; Diener \& Lucas, 1999). Despite of conceptual overlap 
between extraversion and well-being, we suggest resilience is a mediating factor to understand the influence of extraversion on well-being. Research has established that resilience has a positive impact on employee well-being at workplace (Grant et al., 2009; Pipe et al., 2012). Also, workplace performance is known to be influenced by resilience (Ivan et al., 2015; Grant et al., 2009). Accordingly, we hypothesize that:

Hypothesis 5: Resilience mediates the association between extraversion and well-being.

\section{Job performance and satisfaction}

Job satisfaction is an important construct for job performance (Judge, Thoresen, Bono, \& Patton, 2001); and life satisfaction (Judge \& Watanabe, 1993). Job satisfaction is defined as “a pleasurable or positive emotional state resulting from the appraisal of one's job or job experiences" (Locke, 1983, p.1300). High levels of job satisfaction lead to reduced employee turnover (Hom \& Griffeth, 1995; Tett \& Meyer, 1993). Well-being has been associated with life satisfaction and overall positive mood (Diener et al., 1998). Research also points to the influence of well-being on job satisfaction and performance (Grant et al., 2009; Robertson, Cooper, Sarkar \& Curran, 2015). Job satisfaction is also positively associated with extravert and non-neurotic employees at work (Templer, 2012). While the association between personality traits, values, job performance and job satisfaction has been explored in earlier studies (Hurtz \& Donovan, 2000; Judge \& Bono, 2001), we suggest that well-being is associated with job satisfaction (Grant et al., 2009; Robertson, Cooper, Sarkar \& Curran, 2015). Specifically, an individual's overall well-being influences their ability to work and job performance. Well-being provides the inner mechanisms to work hard and consequently influence job satisfaction. Therefore, we hypothesize that:

Hypothesis 6: Well-being is associated with job satisfaction via job performance.

Positive work experiences play a pivotal role in promoting resilience for individuals in the workplace (Vanhove, Herian, Harms \& Lester, 2016). Resilient individuals will have the 
ability to recover from difficult workplace experiences (Soanes \& Stevenson, 2006) and influence job performance (Judge et al., 2001). Low resilience at workplace leads to increased stress and negative impact on work performance (Keyes \& Grzywacz, 2005). Research has already established that job performance is intrinsically associated with job satisfaction (Judge et al., 2001). We suggest that resilience provides the inner mechanisms to work hard and consequently influence job satisfaction. This gives rise to our next hypothesis: Hypothesis 7: Resilience is associated with job satisfaction via job performance.

\section{METHOD}

\section{Participants}

We conducted two empirical studies to address our research questions. This approach is useful to analyze the relationships between the independent and dependent variables as proposed in the study's hypotheses.

Study 1 participants comprised of 195 respondents from the University of New South Wales (UNSW), Australia. The proposed study was approved by the UNSW ethics committee. Majority of the respondents had work experience. As mentioned above, the aim of this study was to explore the association between personality traits, values and moral foundations. The survey was operationalized in a laboratory-based setting and received a satisfactory response rate. Forty-four percent $(44.6 \%)$ of the respondents were male and $47.2 \%$ were female $(8.2 \%$ did not indicate their gender). Participants' age ranged from 18 and 47, with younger than 21 years $(54.9 \%)$ and only a few older than 35 years $(2.1 \%)$. Overall response rate was $30 \%$.

\section{Measures and analytical procedure}

The following measures from the extant literature were employed in the measurement of key constructs for this study. The Moral Foundations Questionnaire (MFQ) (Graham, Haidt, \& Nosek, 2009) is a 32-item questionnaire that measures the degree to which a person relies on 
each of the five moral foundations: harm/care, fairness/reciprocity, in-group/loyalty, authority/respect, and purity/sanctity. The scale was built to measure "individualizing" and "binding" moral foundations. Individualizing foundations are harm/care, fairness/reciprocity; and binding foundations are in-group/loyalty, authority/respect, and purity/sanctity. An example of item is 'Compassion for those who are suffering is the most crucial virtue'. The alpha reliabilities for the scale are as follows: in-group $\alpha=.70$, authority $\alpha=.75$, purity $\alpha=$ $.84 ;$ harm $\alpha=.67$, and fairness $\alpha=.67$.

The International Personality Item Pool (IPIP) (Goldberg, 1999) is a 50-item scale targeting the five-factor model personality factors to assess the dimensions of neuroticism, extraversion, openness, agreeableness, and conscientiousness. The 5-point Likert scale operates with 1 'very accurate' to 5 'very inaccurate', and 16-items are reverse-scored. An example of item is 'Am interested in people'. According to Goldberg (1999), the alpha reliabilities for the scale are as follows: conscientiousness: .81; extraversion: .86; agreeableness: .77; neuroticism: .86; and openness: .82 (see Goldberg 2014). For this study, we specifically focused on extraversion and neuroticism, obtained acceptable reliabilities (i.e., extraversion: .88 and neuroticism: .86).

Additionally, we employed the established value scale by Schwartz (Schwartz, 1992). The Schwartz Value Scale (SVS) is an inventory with 7-point Likert-type scale: 0=not important; $3=$ important; $6=$ very important; and $7=$ of supreme importance. The inventory has 56 singlevalue items representing 10 motivationally distinct value dimensions, which include openness to change, self-transcendence, self-enhancement, and conservation. An example of item is '_EQUALITY (equal opportunity for all)'. The reliabilities were in the range of $\alpha=.80$ to $\alpha$ $=.90$.

Emotional Competence test: We employed Self-report emotional intelligence test (SREIT) (Schutte et al., 1998) to measure emotional wellbeing. SREIT is a 33-item scale which 
measures emotional competence in the areas of perception of emotions, management of individual and others' emotions. Good internal consistency was found to this scale (Brackett \& Mayer, 2013).

\section{STUDY 1 RESULTS AND DISCUSSION}

We utilized SPSS and AMOS for data analysis to understand the association between personality traits, values, moral foundations, resilience, well-being, job performance and job satisfaction. Hypotheses 1 to 3 were tested simultaneously using Structural Equation Modeling - SEM (AMOS version 17.3). SEM was most appropriate method for the analysis based on the nature of the study (i.e. survey from laboratory based, working and student population). The results of the current study support the three hypotheses. Means, standard deviations and correlations between the variables are shown in Table 1. Path Analysis (AMOS version 17.3) was used to test hypotheses 1 to 3 . The relationship between personality, values and moral foundations was tested in two structural models. In addition, our sample of 195 participants and 8 cases per parameters meet the requirement (Kline, 2011).

\section{Model Fit Summary}

As pointed above, values mediated the relationship between personality, values and moral foundations. Parameter estimates are summarized in figure 1 as per the hypothesized models. They show the Chi- square $=35.7, \mathrm{df}=11 ; \mathrm{CFI}>0.93 ; \mathrm{RMSEA}<0.10 ; \mathrm{TLI}>.83 ; \mathrm{PGFI}>$ .29, GFI $>.95$. Parameter estimates are summarized in figure 2 . Relatively good fit was obtained in all hypothesized models: Chi- square $=23.8, \mathrm{df}=9 \mathrm{CFI}>0.39 ;$ RMSEA $<0.35$.

Insert Table 1 and Figure 2 about here 
As can be seen in figure 1, support is obtained for hypothesis 1 , where extraversion is positively associated with emotional wellbeing via harm/care $($ beta $=0.18, p<0.001)$ and fairness/reciprocity $($ beta $=0.15, p<0.001)$. Extraversion directly predicts individualizing harm/care, and fairness/reciprocity. We suggest that extraverts are by nature social and open to new experiences and reward oriented (Austin, Salofske, \& Egan, 2005; Olson \& Weber, 2004) based on their biological sensitivity to rewards (e.g., Jackson, 2005). The conceptual overlap between extraversion and power (Patterson et al., 1987) points to their association to harm/care, and fairness/reciprocity. We suggest that these findings will have positive implications for resilience and well-being.

The findings supported hypothesis 2 , where achievement and power play mediating role between extraversion and wellbeing ( bet $a=-0.17, p<0.001$; beta $=0.14, p<0.001)$. Support is also found for the hypothesized mediation of individual moral foundations harm/care and fairness and emotional wellbeing $($ beta $=0.15, p<0.001$; beta $=0.18, p<0.001)$. These findings are consistent with the research that individuals who score high on extraversion are largely motivated by social reward (e.g., Austin, Salofske, \& Egan, 2005) based on their biological sensitivity to rewards (Jackson, 2005).

Partial support is found for the mediating role of universalism between extraversion and individualizing moral foundations of harm/care and fairness/reciprocity. Individuals who score high on power and achievement are driven by self enhancement. Therefore, logically individuals with power and achievement values are more likely to be resilient. The important finding is that power was positively associated with extraversion and there was significant association with achievement. The results complement the existing research that individuals with self-enhancement values (Schwartz, 1992; 1994; 2005). Partial support is found for hypothesis 3, where universalism is not associated with extraversion but positively associated with emotional wellbeing via individualized moral 
foundations harm/care $($ beta $=0.18, p<0.001)$ and fairness/reciprocity $($ beta $=0.15, p<$ 0.001). These results are generally consistent with suggestion that personality traits and values predict moral foundations. The positive association between universalism and individualizing moral foundations of harm/care and fairness/reciprocity is consistent with Schwartz's (1992) theory that universalism is associated with social justice, equality, and broadmindedness. Furthermore, consistent with the hypothesis, benevolence plays a mediating role between extraversion and group binding moral foundations in-group, authority and purity. Benevolence is negatively mediated by extraversion (beta $=-0.25, \mathrm{p}<0.001$ ). Support is found for the mediating role of benevolence between extraversion and binding moral foundations in-group, authority and purity. Overall, partial support was found for hypothesis 3.

\section{Study 2}

To recap, the aim of study 2 is to empirically confirm the above relationships in a different context as well as investigate the association extraversion, individual moral foundations, well-being, resilience, job performance and job satisfaction. As such hypotheses 4-7 were tested in study 2 .

\section{METHOD}

\section{Participants}

The study's participants comprised of 257 participants from India. The survey distributed to more than 400 potential participants. The sample has a response rate was $64.2 \%$. The participants include full-time employment 24.5\%; working (part-time) students (64.9\%) and remaining did not mention their work experience. Fifty-three percent $(53.3 \%)$ were male, $42.8 \%$ were female and $3.2 \%$ did not indicate their gender. Participants' were practitioners with age ranging from 18 years to 55 years. 


\section{Measures and analytical procedure}

For this study, we employed many measures used in study 1 such as the: $M F Q, I P I P$ and value scale by Schwartz. In addition, we also measured well-being by using the Satisfaction with Life Scale (SWLS) (Diener, Emmons, Larsen, \& Griffin. 1985). The SWLS is a 5-item scale designed to measure of cognitive judgmental components of subjective well-being. The scale records the participants' answers on how much they agree or disagree with each of the given 5 -items by using a 7-point scale. The scale items range from 7 strongly agree to 1 strongly disagree. The SWLS has been noted as an appropriate instrument to measure subjective wellbeing (Pavo \& Diener, 1993).

Psychological resilience was measured by using the Ego-Resilience Scale (Block \& Kremen, 1996). This consists of 14-items with 4-point Likert measure, ranging from 1 strongly disagree to 4 strongly agree. An example of item is 'I am more curious than most people'. The reported Cronbach's alpha reliability for this scale was .76 (Block \& Kremen, 1996). Job Performance was measured using Johnson's (1998) six-item scale. The six-item scale consists with 5-point Likert measure, ranging from 1 (Does not apply at all) to 5 (Applies very strongly). An example of item is 'I work hard and do my job to the best of my abilities'. This measure was found to have good internal reliability $(\alpha=0.75)$. According to Johnson, high scores on this scale indicate high levels of job performance and measure of overall productivity.

Job Satisfaction was measured using Warr and Payne's (1983) scale. It consists of threeitems that are measured on a five-point Likert-type scale. The three items contain: 'How much do you enjoy your job? $(I=I$ don't enjoy it; 5 = I really enjoy my job and couldn't enjoy it more.). According to the authors, high scores on this measure indicate high levels of job satisfaction. Cronbach's alpha reliability for this scale is .83 . 
Hypotheses 4 to 7 were tested simultaneously using SEM (AMOS version 24) via path analysis. The results of the current study support the hypotheses. Means, standard deviations and correlations between the variables are shown in table 2. Our sample size of 257 participants and 7 cases meet the requirement per parameters (Kline, 2011).

\section{Model Fit Summary}

Structural model tested the relationship between extraversion, values, moral foundations, well-being, resilience, job performance and job satisfaction. Parameter estimates are summarized in figure 2 as per the hypothesized models. They show the Chi- square $=40.5$, df $=32 ; \mathrm{CFI}>0.95 ; \mathrm{RMSEA}<0.03 ; \mathrm{RFI}<0.76 ; \mathrm{RMR}<0.13$; $\mathrm{TLI}<0.93 ; \mathrm{PCFI}<0.65 ; \mathrm{GFI}>$ .97 and AGFI > .94.

Insert Table 2 and Figure 3

As can be seen in figure 2, support is obtained for hypothesis 4 where extraversion is positively associated with resilience $($ beta $=0.24, p<0.001)$ and harm/care $($ beta $=0.14, p<$ $0.001)$ and fairness/reciprocity $($ beta $=0.09, p<0.001)$. As mentioned earlier, extraverts are by nature social and driven (Austin, Salofske, \& Egan, 2005) and this is naturally associated with resilience. Extraversion also positively predicts harm/care $($ beta $=0.14, p<0.001)$ and harm/care positively predicts well-being $($ beta $=0.20, p<0.001)$ and there is some association between extraversion and well-being ( $b e t a=0.10, p<0.001)$, thus providing partial support for hypothesis. In support of hypothesis 5, resilience plays a mediating role by positively associating with extraversion $($ beta $=0.24, p<0.001)$, well-being $($ beta $=0.26, p<$ $0.001)$ and extraversion $($ beta $=0.10, p<0.001)$.

We found reasonable support for the hypothesized association between neuroticism and individualizing moral foundations harm/care, and fairness/reciprocity. Neuroticism by nature 
is associated with focusing on self and emotions (Jeronimus, Riese, Sanderman, \& Ormel, 2014) and therefore may have supported individualized moral foundations, especially harm/care that has a significant emotional component, which facilitates ground for building resilience.

In partial support of hypothesis 6, the direct association between well-being and job satisfaction, well-being and job performance is not strong. But the association between job performance and job satisfaction is strong ( $b e t a=0.22, p<0.001)$. In support of hypothesis

7 , there is no association between resilience and job satisfaction, but there is a strong positive association between resilience and well-being $($ beta $=0.26, p<0.001)$ and job performance (beta $=0.22, p<0.001)$. Thus, this hypothesis is partially supported. In additional analysis, we found power was negatively associated with fairness $($ beta $=-0.13, p<0.001)$ and achievement was positively associate with job performance (beta $=0.20, p<0.001)$. These findings show the logical consistency between study 1 and study 2 .

\section{DISCUSSION}

This research explored two studies and examined the relationship between extraversion (Costa \& McCrae, 1992), values of power, achievement, benevolence, and universalism (Schwartz, 1992); and individualizing harm/care, and fairness/reciprocity; binding ingroup/loyalty authority/respect, and purity/sanctity moral foundations (Graham, Haidt, \& Nosek, 2009), and its association with well-being, resilience, job performance and job satisfaction. The distinctive contribution this study offers to the literature on well-being and resilience is that it identifies the relationship paths between individual moral foundations and individual personality trait of extroversion to influence resilience. We further note the relationship of a strong association between resilience and wellbeing. Overall, personality trait and moral foundations are key predictors of both the individual well-being and resilience. This study also contributes to the literature on moral foundations theory (Graham, 
Haidt, \& Nosek, 2009) by assessing the influence of extraversion, neuroticism and values on individualizing and binding moral foundations (Gary \& Bates, 2011). Earlier cross-sectional studies have suggested that extraversion is positively associated with pleasure orientation (e.g., risk-taking behaviors) (Smillie, Cooper, Wilt, \& Revelle, 2012; Tamir, 2009). This study (study 1) also confirmed that extraversion was positively associated with selfenhancement value of power. Building on this, we found that extraversion was also positively associated with welfare-oriented values (e.g. Benevolence) and individualized moral foundation. Employing power and achievement assisted to understand psychological wellbeing. The results also suggest that the negative association between extraversion and benevolence leads to negative association between binding moral foundations in-group, authority and purity. Further, this research found no association between neuroticism and welfare-oriented values of universalism and benevolence. Therefore, based on the findings one can conclude that extraverts have ability for self-enhancement and pleasure orientation as well as taking part in the welfare of others.

Existing research also indicates that extraversion is positively associated with subjective well-being and neuroticism is negatively associated with subjective well-being and greater happiness (Enns \& Cox, 1997; Ryff, Keyes \& Shmotkin, 2002). The literature also suggests that individuals who score high on neuroticism respond intensely to negative experiences in life whereas extroverts respond positively to various social interactions (Enns \& Cox, 1997). Furthermore, research suggests that individuals with high extraversion, low neuroticism as being those who are associated with high levels of well-being (Ryff, Keyes \& Shmotkin, 2002). Our results have established a positive association between extraversion, individual moral foundations, resilience, well-being, job performance and job satisfaction. Therefore, we argue that this study offers a distinctive contribution to the literature on well-being and resilience in the following manner. We first note that personality impacts values such that 
power and achievement or self-enhancement values, which often have a negative connotation are important and pivotal biological values for someone to remain resilient as these values give individuals the ability to remain in have high levels of self-efficacy. Second, the study notes that values of benevolence and universalism, which are also referred to as compassionate values or values that have a positive connotation, also form a basis for the biological mechanisms of resilience because they focus on individual moral foundations of fairness/harm care. Therefore, individualized moral foundations are a better predictor of collective human well-being, resilience and job satisfaction than group moral foundations. Finally, it is surprising that we found no relations between the personality dimensions of agreeableness and moral foundation harm/care, due to their theoretical overlap and similarity in content (Gary \& Bates, 2011). Therefore, at this point, we see this as a limitation of the study and express a need for replication of this study, using diverse samples, possibly in cross-cultural contexts that could shed more light on the presumed relationship between agreeableness and harm/care. Overall, the evidence points to the validity of hypothesized models (see Figures 1, $2 \& 3$ ) and that the personality traits of extraversion can influence directly individualizing moral foundations and indirectly binding moral foundations through values. This finding has theoretical implications for the literature on resilience and wellbeing, which is discussed in the following section. Research has established that personality traits have a biological base (e.g., Cloninger et al., 1993; Gray, 1970; Jackson, 2005) and that human values derive from the biological needs of individuals for their survival (Schwartz, 1992, 1994, 2005). Moral foundations theory was proposed by social and cultural psychologists, who in their cross-cultural research, argued that innate psychological systems are the foundations to morality (Graham, Nosek, Haidt, Iyver, Koleva \& Ditto, 2011; Haidt \& Joseph, 2004). In this paper, Study 1 utilized biological based personality traits and values to provide further strength to the moral foundation theory. Overall, the conceptual overlap and 
empirical association have now been established between personality traits, values, moral foundations and psychological wellbeing in Study 1. In Study 2, our results suggest that personality influences wellbeing and resilience via moral foundations. Furthermore, a strong association was noted between wellbeing and resilience. These findings complement the existing research which argues that wellbeing promotes resilience (Steel, Schmidt, \& Shultz, 2008; Diener \& Lucas, 2003). Based on our two studies, the first study found personality, values and moral foundations influence wellbeing, whereas, the second study provided further logical consistency and argued that personality and moral foundations influence wellbeing and resilience. In a recent study, Athota and Malik (2019) found the personality and values influence individual well-being at workplace, which also affect their resilience, job satisfaction as well as their ability to deliver innovation performance.

\section{THEORETICAL AND MANAGERIAL IMPLICATIONS}

Contrary to our findings, Gary and Bates (2011) found that extraversion was associated with binding moral foundations and neuroticism was associated with individualized moral foundations. Graham et al. (2009) suggested that moral foundations are evolved psychological intuitions, while Schwartz (1992) suggested that values are the result of biological needs of human beings. Gary and Bates's (2011) research was not clear about this distinction between moral foundations and values. Therefore, the current findings examined this difference and provided evidence on how biological values can influence intuitive based moral foundations.

From a theoretical point of view, this research has made several contributions to the moral foundation theory (Graham, Haidt \& Nosek, 2009) and the emerging literature on employee well-being and resilience. First, and most importantly, results are reasonably consistent of the hypotheses presented in this study. Second, the influence of extraversion on resilience via 
moral foundations and values is an important finding. Third, the results also point to the influence of resilience on job performance and satisfaction. We are not aware of any research to date, which has examined the role of extraversion predicting resilience via individual moral foundations. These predictions are important and explain resilience and well-being at both the individual and organizational levels. Further, while neuroticism predicted moral foundations, no association was found with resilience and job satisfaction. We suggest that this finding demonstrates the logical consistence of the moral foundations theory and recent findings on narcissism and counterproductive work behavior (e.g. Grijalva \& Newman, 2015; Templer, 2012). Also, the current findings support the credibility of MFT (see Haidt \& Joseph, 2011). Moreover, understanding the association between personality, moral foundations, values and resilience helps the organization meet the current challenges at workplace. Overall, the distinctive contribution of this research (two studies) is on establishing how personality traits of extraversion and compassionate/self-transcendence and self-enhancement values, respectively, of benevolence and universalism and power and achievement, influence individualizing moral foundations and employee resilience, wellbeing and job satisfaction. In line with earlier research, we find support that individual moral foundations promote human well-being (Kesebir \& Diener, 2008).

The study points to several managerial implications. Overall, our findings highlight that managers must not underestimate the importance of individual moral foundations in an organizational context, especially as it also impacts resilience, well-being and job performance and job satisfaction. Building moral foundations is therefore vital for individuals and people in organizations, especially in times of disruptive change, uncertainty and volatility in business environments. This distinctive is of critical importance as during times of change firms and employees are often confronted with ethical dilemmas and often end-up engaging in unethical decisions, which often have adverse impacts on the subjective well- 
being and resilience of individuals at work. In this regard, managers must invest in situational training to improve the base of individual moral foundations for their overall well-being and resilience. While cognitive and behavioral domains of learning may not be the most appropriate way of imparting such training, firms should engage in case-based, participant centered learning approaches, using an emancipatory learning frame and engage in critical and dialectical thinking. Such an approach would help employees challenge existing frames and paradigms and strengthen their moral foundations so that they are able to deal with the changes much more effectively.

Further, as individual's biologically-based personality traits and values do not change, therefore, as per our findings, managers need to better understand the bases of biologicallybased mechanisms of resilience. For example, individuals who score high on extraversion and have strong binding moral foundations may be better placed focusing on the design and implementation of change. Additionally, managers should promote well-being initiatives for employees, as it is a key predictor of individual resilience and has a positive impact on job performance and satisfaction. By proactively focusing on facilitating the above aspects of well-being and resilience, firms will be able to achieve desired levels of job performance and satisfaction. It is likely that managers who proactively follow such an approach can create more resilient workforce, conducive to managing change and external shocks from the environment. Individual moral foundations are known to have a strong impact on one's caring behaviors and may indeed be a facilitating force for developing the greater good and resilience. Such tendency can be of extreme use in times of natural crisis (Klein, Nicholls, \& Thomalla, 2003; Manyena, 2003). Overall, developing a nuanced understanding of personality traits and moral foundations at an individual level, will help firms gauge their ability to deal with major externally or internally imposed changes and as a consequence focus on developing employee well-being and resilience. 


\section{LIMITATIONS}

The main limitations of the research include: mostly self-report data was used for this study. Though we believe that a person's moral foundations are better known through self-report than any other method, however, peer-report studies on moral foundations are also needed for estimating the various views on a person's morality. Another limitation is that study 1 is that although the sample is of students. However, a large majority of them have work experience. Further, as they are well past their formative years, their biologically based personality traits, values and moral foundations are established. Similarly, though there are students included in the sample for study 2 , the literature is quite well established that an individual's personality, values and moral foundations do not change over a sustained period of time. Nevertheless, this calls for further studies of individuals focusing exclusively on working population.

We also suggest further data collection should focus on sector specific data to further explore any differences due to industry sectors. Additionally, future research can consider the influence of leadership styles, measure of tenure, prior experience and gender to expand the scope of the study. Despite of these limitations, the study helped to reveal that extraversion predicts individual moral foundation, which further influences resilience and well-being in individuals and their job satisfaction and performance in organizations.

\section{CONCLUSION}

In the first part of this research has established how extraversion directly predicted psychological wellbeing through individualizing moral foundations and values of power, achievement, benevolence, and universalism. In the second study, extraversion is a key predictor of individuals' moral foundations, which influence resilience and well-being.

Overall, the cross-national studies revealed that personality, values and moral foundations influence wellbeing, resilience, job performance and job satisfaction. One potential extension of this research is to find the association between Cloninger, Svrakic, \& Przybeck's (1993) 
personality theory and individual moral foundations, and theoretical implications on resilience and well-being. We argue that individual moral foundations and self-transcendence values are fundamentally important in dealing with crisis in $21^{\text {st }}$ century organizational challenges and uncertainties created by events like Brexit; on-going acts of terrorism and financial crisis. We suggest individualizing moral foundations provide a base for resilience in dealing with individual and organizational level challenges. We also suggest that values and moral foundations facilitate ground for resilience. We further argue that individualized moral foundations are superior as compared to binding group moral foundations in facilitating collective well-being.

This study empirically demonstrated the link between personality and values of power, achievement, universalism, benevolence (Schwartz, 1992), and moral foundations (Graham, Haidt, \& Nosek, 2009). Results were generally consistent with the proposed model; extraversion directly predicted individualizing moral foundations and values mediated between extraversion and binding moral foundations. The key findings are that individual moral foundations are pivotal in dealing uncertainty of mass migration, counter the fears of terrorism promoting resilience and collective well-being.

\section{REFERENCES}

Allport, G. W. (1961). Pattern and growth in personality. New York: Holt, Rinehart \&Winston.

Athota, V. S. (2016). Foundations and future of well-being: How personality influences happiness and well-being, Impact of Organizational Trauma on Workplace Behavior and Performance. (Advances in Human Resources Management and Organizational Development Series), Business Science Reference press, pp. 279 - 293.

Athota, V. S., \& O'Connor, P. J. (2014). How approach and avoidance constructs of Personality and emotional management predict core human values. Learning and Individual Differences, 31, 51-58.

Athota, V. S., and Malik, A. (2019). Managing Employee Well-being and Resilience for Innovation: Evidence from Knowledge-intensive Service Industries. Switzerland: Springer Nature Switzerland AG. 
Athota, V. S., \& Roberts, R. D. (2015). How Extraversion + leads to problem-solving ability. Psychological Studies, 60, 332-338.

Block, J., \& Kremen, A. M. (1996). IQ and ego-resiliency: Conceptual and empirical connections and separateness. Journal of Personality and Social Psychology, 70, 349361.

Boyatzis, R.E., Goleman, D., and Rhee, K. (2000). Clustering competence in emotional intelligence: Insights from the Emotional Competence Inventory (ECI). In R. Bar-On and J.D.A. Parker (eds.). Handbook of Emotional Intelligence, San Francisco: JosseyBass.

Brackett, M.A., \& Mayer, J.D. (2003). Convergent, discriminant, and incremental validity of competing measures of emotional intelligence. Personality and Social Psychology Bulletin, 29, 1147-1158.

Carmeli, A. \& Gittell, J.H., 2009. High-quality relationships, psychological safety, and learning from failures in work organizations. Journal of Organizational Behavior, 30(6), pp.709-729.

Carmeli, A., Yitzhak-Halevy, M. \& Weisberg, J., 2009. The relationship between emotional intelligence and psychological wellbeing. Journal of Managerial Psychology, 24(1), pp.66-78.

Costa, P. T., Jr., \& McCrae, R. R. (1992). Revised NEO Personality Inventory (NEO-PI_R) and NEO Five-Factor Inventory (NEO-FFI) manual. Odessa, FL: Psychological Assessment Resources.

Costa, P. T., Jr., \& McCrae, R. R. (1980). Influence of extra- version and neuroticism on subjective well-being: Happy and unhappy people. Journal of Personality and Social Psychology, 38(4), 668-678.

Cloninger, C. R. (1987). A systematic method for clinical description and classification of personality variants. Archives of General Psychiatry, 44, 573-588.

Cloninger, C. R., Svrakic, D. M., \& Przybeck, T. R. (1993). A psychobiological model of temperament and character. Archives of General Psychiatry, 50, 975-990.

Curtis, J., Billingslea, R., \& Wilson, J. (1988). Personality correlates of Moral Reasoning and attitudes toward authority. Psychological Reports, 63(3), 947-954.

DeNeve, K. M., \& Cooper, H. (1998). The happy personality: A meta analysis of 137 personality traits and subjective well-being. Psychological Bulletin, 124, 197-229.

De Raad, B., \& van Oudenhoven, J. P. (2008). Factors of values in the Dutch language and their relationship to factors of personality. European Journal of Personality, 22, 81108.

Diener, E., Emmons, R. A., Larsen, R. J., \& Griffin, S. (1985). The Satisfaction with Life Scale. Journal of Personality Assessment, 49, 71-75.

Diener, E., \& Lucas, R.R. (1999). Personality and subjective well-being. In E. Kahneman, E. Diener, \& N. Schwarz (Eds.), Well-being: The foundations of hedonic psychology (pp.213-229). New York: Russell Sage Foundation. 
Dollinger, S. J., Leong, F. T. L., \& Ulicni, S. K. (1996). On traits and values: With special reference to openness to experience. Journal of Research in Personality, 30, 23-41.

Dukerich, J. M., Waller, M. J., George, E., \& Huber, G. P. (2000). Moral intensity and managerial problem solving. Journal of Business Ethics, 24(1), 29-38.

Dunn, L. B., Iglewicz, A., \& Moutier, C. (2008). A conceptual model of medical student well-being: promoting resilience and preventing burnout. Academic Psychiatry, 32(1), 44-53.

Enns, M. W., \& Cox, B. J. (1997). Personality dimensions and depression: Review and commentary. Canadian Journal of Psychiatry, 42(3), 274-284.

Fredrickson, B. L. 2001. The role of positive emotions in Positive Psychology: The broadenand-build theory of positive emotions. American Psychologist, 56(3), 218-226.

Fredrickson, B. L., Tugade, M. M., Waugh, C. E., \& Larkin, G. R. 2003. What good are positive emotions in crises? A prospective study of resilience and emotions following the terrorist attacks on the United States on September 11th, 2001. Journal of Personality and Social Psychology, 84, 365-376.

Furnham, A., Hyde, G., \& Trickey, G. (2014). Do your dark side traits fit? Dysfunctional personalities in different work sectors, Applied Psychology: An International Review, 63(4), 589-606.

Gary, J.L., \& Bates, C.T. (2011). From left to right: How the personality system allows basic traits to influence politics via characteristic moral adaptations. British Journal of Psychology, 102, 546-558.

Gray, J. A. (1970). The psychophysiological basis of introversion-extraversion. Behavior Research and Therapy, 8, 249-66.

Goldberg, L. R. (1999). A broad-bandwidth, public-domain, personality inventory measuring the lower-level facets of several five-factor models. In I. Mervielde, I. Deary, F. De Fruyt, \& F. Ostendorf (Eds.), Personality Psychology in Europe: Vol. 7 (pp. 7-28). Tilburg, The Netherlands: Tilburg University Press.

Goldberg, L. R., Johnson, J. A., Eber, H. W., Hogan, R., Ashton, M. C., Cloninger, C. R., \& Gough, G.H. (2006). The International Personality Item Pool and the Future of Public-Domain Personality Measures. Journal of Research in Personality, 40(1), 8496.

Goldberg, L.R. (2014). NEO Domains Table (October 19, 2014). Retrieved from http://ipip.ori.org/newNEO_Domains

Goleman, D. (1995). Emotional intelligence. New York, NY, England: Bantam Books, Inc.

Goleman, D. (1996). Emotional intelligence. Why It Can Matter More Than IQ. Learning, 24 (6), 49-50.

Graham, J., Haidt, J., \& Nosek, B.A. (2009). Liberals and conservatives rely on different sets of moral foundations. Personality Processes and Individual Differences, 96, 1029-1046.

Graham, J., Nosek, B.A., Haidt, J., Iyer, R., Koleva, S., \& Ditto., P.H. (2011) Mapping the moral domain. Journal of Personality and Social Psychology 101, 366-385. 
Grant, A. M., Curtayne, 1., \& Burton, G. (2009). Executive coaching enhances goal attainment, resilience and workplace wellbeing: A randomized controlled study. The Journal of Positive Psychology, 4, 396-407.

Greene, J. D., \& Haidt, J. (2002). How (and where) does moral judgment work? Trends in Cognitive Science, 6, 517-523.

Grijalva, E. \& Newman, A. D., (2015). Narcissism and Counterproductive Work Behavior

(CWB): Meta-Analysis and Consideration of Collectivist Culture, Big Five Personality, and Narcissism's Facet Structure. Applied Psychology: An International Review, 64, 93 126

Haidt, J. (2008). Morality. Perspectives on Psychological Science, 3, 65-72.

Haidt, J. (2012). The Righteous Mind: Why Good People Are Divided by Politics and Religion. New York, NY: Pantheon.

Haidt, J., \& Graham, J. (2007). When morality opposes justice: Conservatives have moral intuitions that liberals may not recognize. Social Justice Research, 20, 98-116.

Haidt, J., \& Joseph, C. (2004). Intuitive ethics: How innately prepared intuitions generate culturally variable virtues. Daedalus, Fall, 55-66.

Haidt, J., \& Joseph, C. (2011). How Moral foundations Theory Succeeded in Building on Sand: A Response to Suhler and Churchland, Journal of Cognitive Neuroscience, 23(9), 2117-2122.

Haidt J, Kesebir S. Morality. In: Fiske ST, Gilbert D, Lindzey G, editors. Handbook of Social Psychology. 5th Edition. Hoboken, NJ: Wiley; 2010. pp. 797-832.

Hamel, G., \& Valikangas, L. (2003). The quest for resilience. Harvard Business Review, $81(9), 52-65$.

Hobfoll, S. E., Hall, B. J., Canetti-Nisim, D., Galea, S., Johnson, R. J., \& Palmieri, P. A. (2007). Refining our understanding of traumatic growth in the face of terrorism: Moving from meaning cognitions to doing what is meaningful. Applied Psychology: An International Review, 56(3), 345-366.

Hom, P. W., \& Griffeth, R. W. (1995). Employee turnover. Cincinnati, OH: South-Western.

Hurtz, G. M., \& Donovan, J. J. (2000). Personality and job performance: The big five revisited. Journal of Applied Psychology, 85, 869-879

Ivan, T. R., Cooper, L. C., Sarkar, M., \& Curran, T. (2015). Resilience training in the workplace from 2003 to 2014: A systematic review. Journal of Occupational and Organizational Psychology, 88, 533-562.

Jackson, C. J. (2005). An applied neuropsychological model of functional and dysfunctional learning: Applications for business, education, training and clinical psychology. Australia: Cymeon.

Jeronimus, B.F., Riese, H., Sanderman, R., \& Ormel, J. (2014). Mutual reinforcement between neuroticism and life experiences: A five-wave, 16-year study to test reciprocal causation. Journal of Personality and Social Psychology, 107(4), 751-64.

Johnson, D. E. (1998). Applied multivariate methods for data analysts. Pacific Grove, CA: Duxbury Press. 
Judge, T. A., \& Bono, J. E. (2001). Relationship of core self-evaluation traits - self-esteem, generalized self-efficacy, locus of control, and emotional stability - with job satisfaction and job performance: A meta-analysis. Journal of Applied Psychology,

$86,80-92$.

Judge, T.A., Thoresen, C.J., Bono, J.E., \& Patton, G.K. (2001b). The job satisfaction-job performance relationship: A qualitative and quantitative review. Psychological Bulletin, 127, 376-407.

Judge, T.A., \& Watanabe, S. (1993). Another look at the job satisfaction-life satisfaction relationship. Journal of Applied Psychology, 78, 939-948.

Junni, P., Saral, R., Taras, V., \& Tarba, S. (2013). Organizational ambidexterity and performance: A meta-analysis. Academy of Management Perspectives, 27(4), 299-312.

Kellezi, B., Reicher, S., \& Cassidy, C. (2009). Surviving the Kosovo conflict: A study of social identity, appraisal of extreme events, and mental well-being. Applied Psychology: An International Review, 58(1), 59-83.

Kesebir, P., \& Diener, E. (2008). In pursuit of happiness: Empirical answers to philosophical questions. Perspectives on Psychological Science, 3, 117-125.

Keyes C. L. M., Grzywacz J. G. (2005). Health as a complete state: the added value in work performance and healthcare costs. Journal of Occupational Environmental Medicine. 47, 523-532.

Klein, R.J.T., Nicholls, R.J., \& Thomalla, F. (2003). Resilience to natural hazards: how useful is this concept? Global Environmental Change, 5, 35-45.

Kline, R. B. (2011). Principles and practice of structural equation modeling. New York, NY: Guilford.

Kobasa, S. C. (1979). Stressful life events, personality, and health: An inquiry into hardiness. Journal of Personality and Social Psychology, 37(1), 1-11.

Kochanska, G., Aksan, N., Penney, S. J., \& Doobay, A. F. (2007). Early positive emotionality as a heterogeneous trait: Implications for children's self-regulation. Journal of Personality and Social Psychology, 93(6), 1054-1066.

Kossek, E.E. \& Perrigino, M.B., (2016). Resilience: A review using a grounded integrated occupational approach. The Academy of Management Annals, 10(1), pp.729-797.

Lamb, D., \& Cogan, N. (2016). Coping with work-related stressors and building resilience in mental health workers: A comparative focus group study using interpretative phenomenological analysis. Journal of Occupational and Organizational Psychology, 89, 474-492.

Larsen. R.J. \& Buss. D.M. (2014). Personality psychology: Domains of knowledge about human nature. ( $5^{\text {th }}$ Edition). New York: McGraw-Hill.

Locke, E.A. (1983). The nature and causes of job satisfaction. In M.C. Dunnette (Ed.), Handbook of industrial and organizational psychology (pp. 1297-1349). New York: Wiley. 
Liu, Y., Wang, Z. \& Lü, W., 2013. Resilience and affect balance as mediators between trait emotional intelligence and life satisfaction. Personality and Individual Differences, 54(7), pp.850-855.

Lyubomirsky, S., \& Lepper, H.S. (1999). A measure of subjective happiness: Preliminary reliability and construct validation. Social Indicators Research, 46, 137 - 155.

Marks, N., \& Shah, H. (2005). A well-being manifesto for a flourishing society. Journal of Mental Health Promotion, 3(4), 9-15.

Manyena, S.B. (2006). The concept of resilience revisited. Disasters, 30, 433-450.

McCrae, R. R. (2000). Trait psychology and the revival of personality and culture studies. American Behavioral Scientist, 44, 10-31.

O'Leary-Kelly, A. M., \& Bowes-Sperry, L. (2001). Sexual harassment as unethical behavior: The role of moral intensity. Human Resource Management Review, 11(1), 73-92.

Ong, A. D., Bergeman, C. S., Bisconti, T. L., \& Wallace, K. A. 2006. Psychological resilience, positive emotions, and successful adaptation to stress in later life. Journal of Personality and Social Psychology, 91: 730 -749.

Pavot, W. G., \& Diener, E. (1993). Review of the satisfaction with life scale. Psychological Assessment, 5, 164-172.

Raynor, D. A., \& Levine, H. (2009). Associations between the five-factor model of personality and health behaviors among college students. Journal of American College Health, 58, 73-81.

Richerson, P., \& Boyd R. (2005). Not By Genes Alone. University of Chicago Press, Chicago.

Robertson, I. T., Cooper, C. L., Sarkar, M., \& Curran, T. (2015). Resilience training in the workplace from 2003 to 2014: A systematic review. Journal of Occupational and Organizational Psychology, 88(3), 533-562.

Roccas, S., Sagiv. L., Schwartz, S. H., \& Knafo, A. (2002). The big five personality factors and personal values. Personality and Social Psychology Bulletin, 28, 789-801.

Rokeach, M. (1979). From individual to institutional values: With special reference to the values of science. In M. Rokeach (Ed.), Understanding human values (pp. 47-70).

New York: Free Press.

Ryff, C.D., Keyes, CLM., \& Shmotkin, D. (2002). Optimizing well-being: the empirical encounter of two traditions. Journal of Personality and Social Psychology 82,10071022.

Salovey, P. \& Mayer, J.D. (1990). Emotional intelligence. Imagination, Cognition, and Personality, 9, 185-211.

Schwartz, S. H. (1992). Universals in the content and structure of values: Theory and empirical tests in 20 countries. In M. Zanna (Ed.), Advances in experimental social psychology 251-65. New York: Academic Press. 
Schwartz, S. H. (1994). Are there universal aspects in the content and structure of values? Journal of Social Issues, 50, 19-45.

Schwartz, S. H. (1996). Value priorities and behavior: Applying a theory of integrated value systems. In C. Seligman, J. M. Olson, \& M. P. Zanna (Eds.), The psychology of values: The Ontario Symposium, Vol. 8 (pp.1-24). Hillsdale, NJ: Erlbaum.

Schwartz, S. H. (2005). Basic human values: Their content and structure across countries. In A. Tamayo \& J. B. Porto (Eds.), Valores e comportamento nas organizações [Values and behavior in organizations] pp. 21-55. Petrópolis, Brazil: Vozes.

Schwartz, S. H. (2006). Basic human values: Theory, measurement, and application. Revue francaise de sociologie.

Schwartz, S. H., \& Bilsky, W. (1987). Toward a universal psychological structure of human values. Journal of Personality and Social Psychology, 53, 550-562.

Shepherd, D. A., Wiklund, J., \& Haynie, J. M. 2009. Moving forward: Balancing the financial and emotional costs of business failure. Journal of Business Venturing, 24(2): 134-148.

Shin, J., Taylor, M.S. and Seo, M.G., 2012. Resources for change: The relationships of organizational inducements and psychological resilience to employees' attitudes and behaviors toward organizational change. Academy of Management Journal, 55(3), pp.727-748.

Smillie, L. D., Cooper, A. J., Wilt, J., \& Revelle, W. (2012). Do extraverts get more bang for the buck? Refining the affective-reactivity hypothesis of extraversion. Journal of Personality and Social Psychology, 103, 306-326.

Soanes, C., \& Stevenson, A. (2006). Oxford dictionary of English. (2 ${ }^{\text {nd }}$ ed.), Oxford, UK: Oxford University Press.

Stankov, L. (2007). The structure among measures of personality, social attitudes, values, and social norms. Journal of Individual Differences, 28, 240-251.

Steel, P., Schmidt, J., \& Shultz, J. (2008). Refining the relationship between personality and subjective well-being. Psychological Bulletin, 134, 138-161.

Suhler, C. L., \& Churchland, P. (2011). Can innate, modular "foundations" explain morality? Challenges for Haidt's moral foundations theory. Journal of Cognitive Neuroscience, 23, 2103-2116.

Tamir, M. (2009). Differential preferences for happiness: Extraversion and trait-consistent emotion regulation. Journal of Personality, 77, 447-470.

Templer, J. K. (2012). Five-Factor Model of Personality and Job Satisfaction: The Importance of Agreeableness in a Tight and Collectivistic Asian Society. Applied Psychology: An International Review, 61(1), 114-129.

Pipe, T.B., Buchda, V.L., Launder, S., Hudak, B., Hulvey, L., Karns, K.E., \& Pendergast, D. (2012). Building personal and professional resources of resilience and agility in the healthcare workplace. Stress and Health, 28, 11-22.

Pizarro, D. A., \& Salovey, P. (2002). On being and becoming a good person: The role of emotional intelligence in moral development and behavior. In J. Aronson (Ed.), Improving academic achievement: Impact of psychological factors on education (pp. 247-266). San Diego: Academic Press. 
Schmutte, P.S. and Ryff, D.C. (1997), "Personality and wellbeing: what is the connection?", Journal of Personality and Social Psychology, Vol. 73, pp. 549-59.

Tett, R. P., \& Meyer, J. P. (1993). Job satisfaction, organizational commitment, turnover intention, and turnover: Path analyses based on meta-analytic findings. Personnel Psychology, 46, 259-293.

Tett, E. (1983). The Development of Social Knowledge. Cambridge: Cambridge University Press.

Turiel, E., Hildebrandt, C., \& Wainryb, C. (1991). Judging social issues: Difficulties, inconsistencies, and consistencies. Monographs of the Society for Research in Child Development. 56:1-103.

Vanhove, J. A., Herian, N. M., Harms, D.P., \& Lester, B.P. (2016). Can resilience be developed at work? A meta-analytic review of resilience-building programme effectiveness. Journal of Occupational and Organizational Psychology, 89, 278-307.

Ucbasaran, D., Shepherd, D.A., Lockett, A. and Lyon, S.J., 2013. Life after business failure the process and consequences of business failure for entrepreneurs. Journal of Management, 39(1), pp.163-202.

Warr, P.B., \& Payne, R. (1983). Affective outcomes of paid employment in a random sample of British workers. Journal of Occupational Behavior, 4, 91-104.

Williams, T. and Shepherd, D., 2016. Building Resilience or Providing Sustenance: Different Paths of Emergent Ventures in the Aftermath of the Haiti Earthquake. Academy of Management Journal, doi: 10.5465/amj.2015.0682. 
Table 1. Inter-correlations, Descriptive Statistics Among Moral Foundations and Personality Traits of Extraversion and

Neuroticism; Values of Universalism, Benevolence, Achievement, and Power; Moral Foundations of Harm/Care, Fairness/reciprocity, In-group/loyalty, Authority/respect, and Purity/sanctity

\begin{tabular}{|c|c|c|c|c|c|c|c|c|c|c|c|c|c|}
\hline & Mean & $\mathrm{SD}$ & 1 & 2 & 3 & 4 & 5 & 6 & 7 & 8 & 9 & 10 & 11 \\
\hline 1.Extraversion & 26.62 & 3.20 & 1 & & & & & & & & & & \\
\hline 2. Neuroticism & 31.48 & 3.70 & $-0.15^{*}$ & 1 & & & & & & & & & \\
\hline 3. Benevolence & 2.30 & 3.20 & $-0.25^{*}$ & 0.16 & 1 & & & & & & & & \\
\hline 4.Universalism & 1.54 & 5.55 & -0.09 & 0.03 & $0.32^{* * *}$ & 1 & & & & & & & \\
\hline 5. Achievement & 0.57 & 2.78 & $0.18^{* *}$ & 0.00 & 0.01 & -0.09 & 1 & & & & & & \\
\hline 6. Power & -5.55 & 5.41 & $0.31^{* *}$ & -0.02 & $-0.50 * *$ & $0.52 * *$ & 0.07 & 1 & & & & & \\
\hline 7. Harm/Care & 25.71 & 3.95 & $-0.23 * *$ & 0.14 & $0.21 * *$ & $0.30 * *$ & 0.07 & $-0.43 * *$ & 1 & & & & \\
\hline 8. Fairness/reciprocity & 25.66 & 3.61 & $-0.25 * *$ & 0.14 & 0.13 & $0.28^{* *}$ & $0.28 * *$ & $-0.39 * *$ & 0.72 & 1 & & & \\
\hline 9. In-group/loyalty & 22.57 & 4.36 & -0.01 & 0.06 & -0.11 & $-0.16^{*}$ & $-0.61 *$ & 0.01 & $0.33 * *$ & $0.38^{* *}$ & 1 & & \\
\hline 10. Authority/respect & 22.82 & 4.18 & -0.03 & 0.06 & $-0.20^{*}$ & $0.27^{* *}$ & $-0.23^{* *}$ & $-0.20 * *$ & $0.21 * *$ & $0.27^{* *}$ & $0.69 * *$ & 1 & \\
\hline 11. Purity/sanctity & 22.24 & 5.37 & -0.05 & 0.04 & -0.12 & $0.27^{*}$ & $-0.18^{*}$ & -0.06 & $0.27 * *$ & $0.19^{* *}$ & $0.61 * *$ & $0.64^{* *}$ & 1 \\
\hline
\end{tabular}

$* * \mathrm{p}<0.01 ; * \mathrm{p}<0.05$ 
Table 2. Inter-correlations, Descriptive Statistics Among Moral Foundations, Personality Traits,

\begin{tabular}{|c|c|c|c|c|c|c|c|c|c|c|c|c|c|}
\hline & Mean & $\mathrm{SD}$ & 1 & 2 & 7 & 8 & 9 & 10 & 11 & 12 & 13 & 14 & 15 \\
\hline 1.Extraversion & 30.76 & 5.76 & 1 & & & & & & & & & & \\
\hline 2. Neuroticism & 29.84 & 5.44 & -0.02 & 1 & & & & & & & & & \\
\hline 7. Harm/Care & 3.35 & .70 & $0.18 * *$ & 0.08 & 1 & & & & & & & & \\
\hline 8. Fairness/reciprocity & 3.49 & .78 & 0.09 & -0.04 & $0.51 * *$ & 1 & & & & & & & \\
\hline 9. In-group/loyalty & 3.47 & .69 & 0.06 & -0.00 & $0.43 * *$ & $0.47^{* * *}$ & 1 & & & & & & \\
\hline 10. Authority/respect & 3.30 & .75 & 0.09 & 0.09 & $0.36 * *$ & $0.42^{* * *}$ & $0.46^{* *}$ & 1 & & & & & \\
\hline 11. Purity/sanctity & 3.18 & .66 & 0.08 & $0.20 * *$ & $0.39 * *$ & $0.33^{* *}$ & $0.40 * *$ & $0.44^{* *}$ & 1 & & & & \\
\hline 12. Resilience & 39.86 & 6.69 & $0.31 * *$ & -0.08 & $0.29 * *$ & $0.23 * *$ & $0.28 * *$ & $0.19 * *$ & $0.31 * *$ & 1 & & & \\
\hline 13. Life Satisfaction & 22.20 & 5.71 & $0.12 *$ & -0.07 & $0.15^{*}$ & 0.10 & $0.12 *$ & $0.18 * *$ & 0.04 & $0.32 * *$ & 1 & & \\
\hline 14. Job Performance & 33.17 & 6.62 & 0.00 & 0.02 & 0.11 & 0.08 & 0.03 & -008 & 0.00 & $0.30 * *$ & 0.02 & 1 & \\
\hline 15. Job Satisfaction & 9.33 & 2.98 & 0.02 & 0.01 & 0.06 & 0.05 & 0.03 & $-0.14 *$ & 0.04 & 0.04 & 0.02 & $0.21 * *$ & 1 \\
\hline
\end{tabular}

$* * \mathrm{p}<0.01 ; * \mathrm{p}<0.05$ 


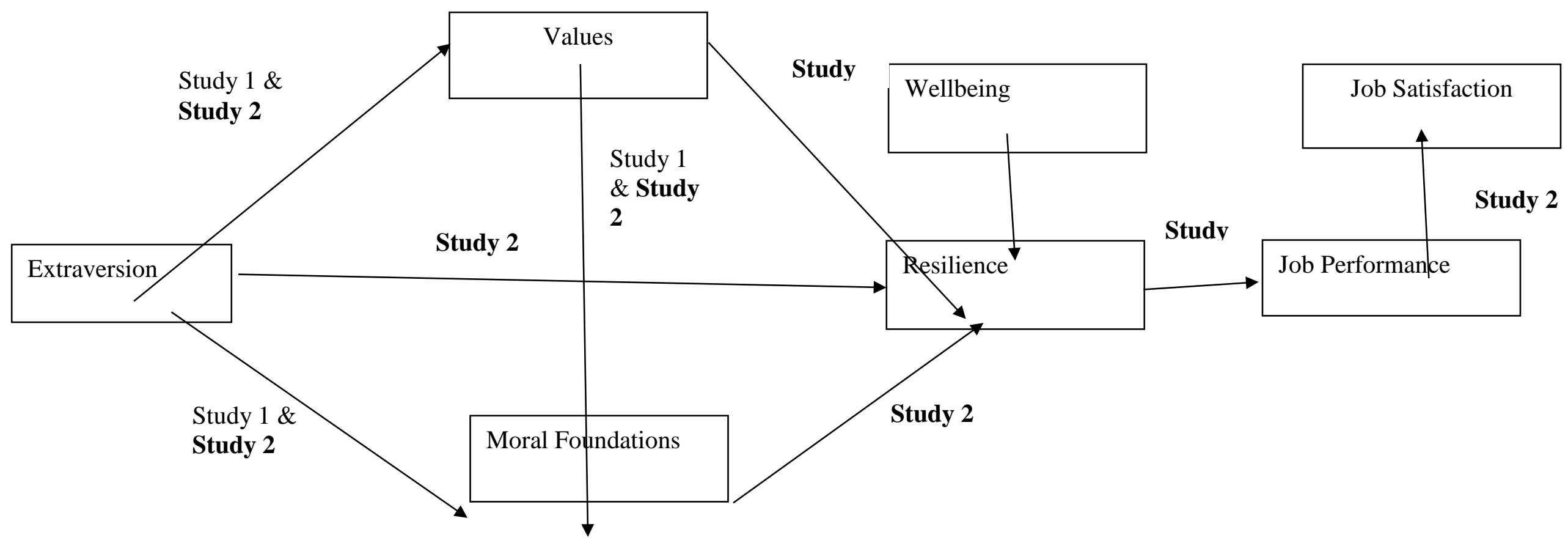

Figure 1. Hypothesized relationships between personality traits, values, moral foundations, well-being, resilience, job performance and job satisfaction 


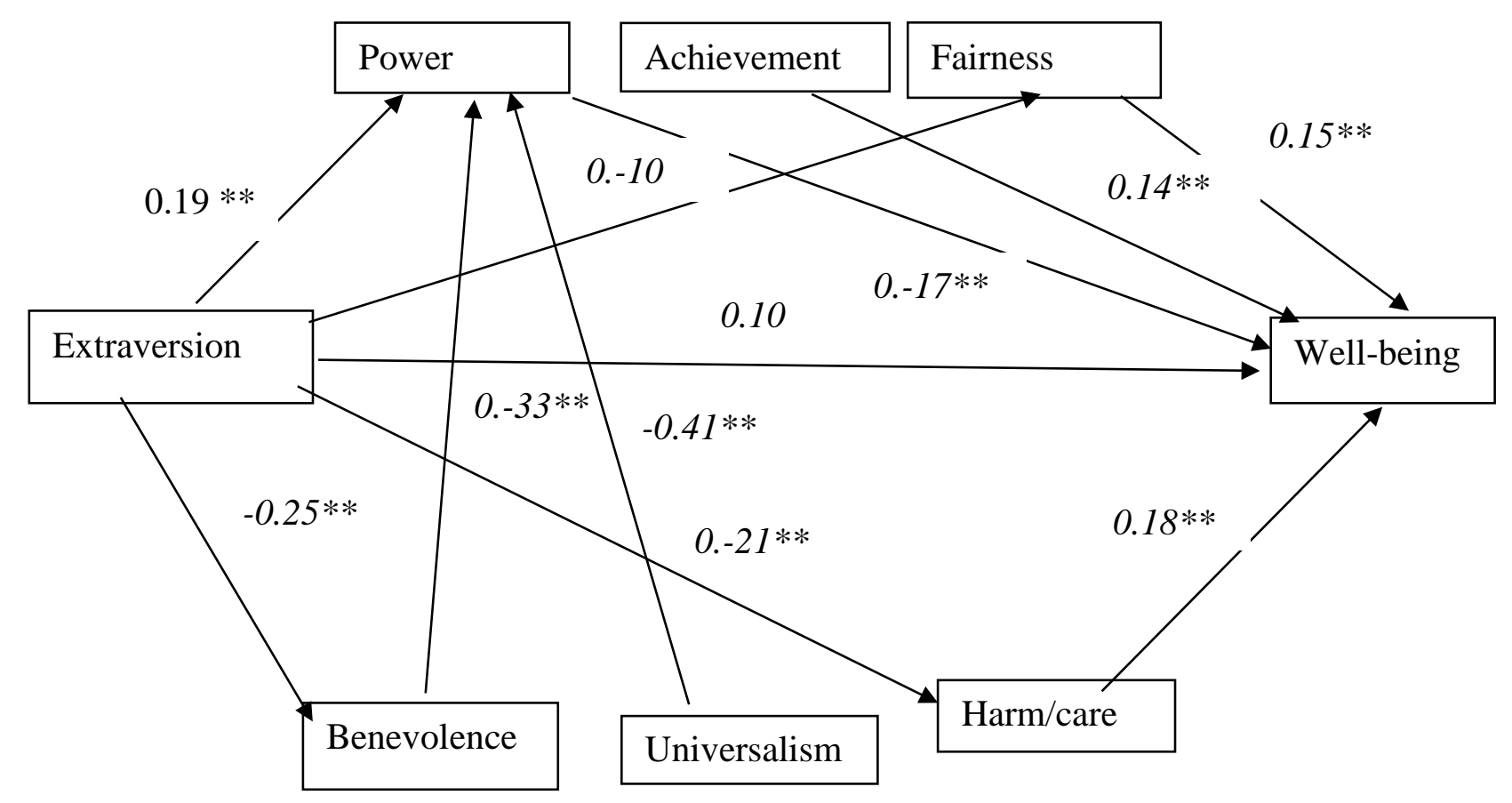

Figure 2. Study 1 Parameter estimates for the hypothesized pathways between personality traits, values, individual moral foundations and, psychological well-being. 
